\title{
Культурный капитал и государственная стратегия России
}

\author{
Опошнянский А.В. \\ Краснодарское высшее военное авиационное училище лётчиков \\ имени Героя Советского Союза А.К. Серова, \\ Россия, 350005, Краснодар, ул. Дзержинского, 135 \\ E-mail: alekseyvo9@yandex.ru
}

\begin{abstract}
Аннотация. На протяжении многих десятилетий конца XX и начала XXI века Россия ищет ответ на цивилизационный вызов о путях своего развития и своей идентичности. «Социализм с человеческим лицом» не был реализован в программах Перестройки и ускорения. Идеологическое решение современный социум ищет на путях постиндустриального социума. Идеология и практика супериндустриальной модели в современных условиях предполагает долговременную стратегию на развитие человеческой субъективности, интеллекта, чувственно-эстетической и физической культуры, стратегию на самораскрытие личности и достижение гармоничного социума. Для этого базовой основой социализации и образования должна стать дидактика понимающей личности. В работе рассмотрены с философско-семиотических позиций пути и некоторые элементы такой стратегии. Автор стремился показать, что понимание есть как субстанция социального бытия, так и основа социального развития.
\end{abstract}

Ключевые слова: культура, культурная политика, общество знания, культурологическая парадигма.

Для цитирования: Опошнянский А.В. 2020. Культурный капитал и государственная стратегия России. NOMOTHETIKA: Философия. Социология. Право. 45 (2): 366-370. DOI 10.18413/2712746X-2020-44-2-366-370

\section{Cultural capital and state strategy of Russia}

\author{
Alexey V. Oposhnyansky \\ Krasnodar highest military aviation college of pilots \\ of a name of the Hero of the Soviet Union A.K. Serov, \\ 135 Dzerzhinsky St, Krasnodar, 350005, Russia \\ E-mail: alekseyvo9@yandex.ru
}

\begin{abstract}
Annotation. For many decades of the late twentieth and early twenty-first century, Russia has been searching for an Answer to the civilizational Challenge about the ways of its development and its identity. «Socialism with a human face» was not implemented in the programs of Perestroika and acceleration. The deconstruction of the USSR did not solve this problem by itself. Modern society is looking for an ideological solution on the path of post-industrial society. However, the mechanisms of «cultural» capital have not yet become the real dominant of social reproduction in Russia. The ideology and practice of the superindustrial model in modern conditions presupposes a long-term strategy for the development of human subjectivity, intellect, sensory-aesthetic and physical culture, a strategy for self-disclosure of the individual and the achievement of a harmonious society. For this purpose, the basic basis of socialization and education should be the didactics of an understanding person. The paper considers the ways and some elements of such a strategy from the philosophical and semiotic positions. The author sought to show that understanding is both the substance of social existence and the basis of social development.
\end{abstract}

Key words: culture, cultural policy, knowledge society, cultural paradigm. 
For citation: Oposhnyansky A.V. 2020. Cultural capital and state strategy of Russia. NOMOTHETIKA: Philosophy. Sociology. Law series. 45 (2): 366-370 (in Russian). DOI 10.18413/2712-746X-2020-44-2-366-370

\section{Введение}

Проблема стратегии социального развития России, а значит и ее идеологии до сих пор не решена. В наибольшей степени к решению стратегических задач идеологии и социальной практики, с нашей точки зрения, приближаются официальные документы, касающиеся стратегии государственной культурной политики. В «Стратегии государственной культурной политики на период до 2030 г.» ${ }^{1}$ наиболее приближенно к необходимым задачам России прописана модель социума, развивающегося на основе не геополитической или сырьевой парадигмы, а на основе культурологической парадигмы. Однако это общая декларация, пока еще не ставшая фактом реальной политической практики в России. Этой общей декларации явно недостаточно. Современная государственная стратегия нуждается не просто в концептах «социальный капитал», «культурный капитал», «символический капитал», «интеллектуальный капитал», а в осознании «тонких настроек» человеческой субъективности, являющейся единственной продуктивной субстанцией человеческой цивилизации.

Для исследования нами использованы социально-семиотический и культурногерменевтический подходы к анализу воспроизводства общества и знания, использованные в работах Б.Г. Богина, М.К. Петрова, В.П. Гриценко.

\section{Основная часть}

Определенным идеологическим прогрессом в нашей стране стало принятие в «Основах государственной культурной политики» [2014, с. 7] культурологической концепции социума, концепции ведущей роли культуры в социальном воспроизводстве, которая была выбрана в качестве приоритета и где понятие культуры пересекается с понятием культурного капитала [там же, с. 9].

Напомним, что культурный процесс есть единство деятельности и коммуникации, в котором созидание новых культурных форм неотделимо от культурной трансляции прошлого опыта, его актуализации и преодоления в критически творческом процессе. Процесс транслирования имеет следующие виды: лично-именную, профессионально-именную [Петров, 1991], концептуально-образовательную, которая в динамичном социуме превращается из ретроспективно-подражательной в проектно-перспективную форму функционирования [Игнатова, Римский, 2012].

Один из фундаторов концепта «социальный капитал», Ф. Фукуяма [Fukuyma, 2001] считает возможным расширить факторы воспроизводства, включив наряду с землей и капиталом «человеческий ресурс». Социальный капитал вбирает в себя знания в широком смысле слова, а также используемые в практике интеракций ценности и нормы. Эта культура производства обеспечивает снижение издержек производства, что продемонстрировало его большую эффективность в Германии, Японии, США.

Концепт «человеческий капитал» эффективен не только в экономическом контексте, но и в культурном, познавательном, в частности, для практики оценивания духовнопознавательной деятельности. Например, понятия «народный артист», «заслуженный артист» - это характеристики социального капитала, органично трансформированного с оценками личностного ресурса с точки зрения культурного капитала. А понятия «канди-

\footnotetext{
${ }^{1}$ Стратегия государственной культурной политики на период до 2030 г.: http://www. consultant.ru/law/hotdocs/45830.html (дата обращения: 05 декабря 2019).
} 
дат наук», «доктор наук», «академик» квалифицируют социальный капитал в союзе с культурно-символическим капиталом ученого. Например, в Японии для обозначения «хранителя значимого нематериального культурного наследия» существует статус и звание «Живое национальное достояние». Это пример интеграции социального и культурного капитала в определенном типе социума, где культурный капитал становится полноправным фактором социального воспроизводства.

Естественно, что каждая сфера профессиональной деятельности - управление, военное искусство - предполагает свой традиционный набор знаний, умений, навыков, который передается от поколения к поколению посредством традиций и обучения, поэтому социальный капитал существует и проявляется в виде профессиональной культуры и ценностей.

Скорость воспроизводства важна для всякого капитала, так как чем выше скорость его обращения, тем выше прибыль. Поэтому все более скоростными становятся процессоры в компьютерах, все более возрастает информационная динамика социумов. В то же время изначальное, коренное свойство культуры - быть социальной памятью, обеспечивать культурную преемственность поколений. Другими словами, важнейшее качество культурного капитала заключено в его способности обеспечивать непрерывность социального развития, истории, прогресс. Однако скорость социализации в современном социуме настолько велика, что возникает опасность разрыва межпоколенных отношений. Актор культуры в условиях информационной цивилизации социализируется не за счет традиции, а как бы вопреки ей.

Кроме того, происходит виртуализация онтологических оснований социума, настоящее и будущее виртуализируются. Вследствие всего этого изменяются идентичности личности и социума. Внедрение человеко-машинного интеллекта в социокультурную коммуникацию также нарушает традиционные каналы коммуникации как в аспекте скорости, так и в аспекте идентичности.

В то же время традиционная культура не исчезает, а продолжает функционировать в структурах гражданского общества, этносознания, участвуя во всех программах и практиках социального действия. Этот аспект проблемы разрабатывает А.П. Люсый, рассматривая проблему о взаимосвязи национального семиозиса и человеческого капитала, подмечая, что интеграция локальных текстов русской культуры в единый интертекст является отражением структуры коммуникативного сообщества россиян на данный период времени [Люсый, 2013]. «Коммуникативное сообщество» - это гражданское, демократическое общество, рождающее высшее качество культуры как социального капитала. Качество политической, правовой, эстетической, нравственной культуры является органической частью культурологического нарратива, порождая особое состояние интеракций социума. Вот это особое коммуникативное состояние интеракций, достигаемое посредством культуры, и является социальным капиталом, интегрирующим технократическую и культурную составляющую некоторого социума.

В практически-дидактической области это означает, что отечественная система образования должна быть в целом ориентирована на гуманитаризацию, развитие национального интеллекта в пользу интерпретационного обучения, на что прозорливо указывал Г.И. Богин [2009], комментируя проведение дидактической реформы в США (National Defence Education Act). Между тем, например, перестройка системы подготовки специалистов высшей квалификации - кандидатов и докторов наук - в России застряла на этапе бюрократического реформирования [Гриценко, 2019]. Интенция творчества на основе понимания не является еще стержнем дидактики для этой подготовки.

Понимание является субстанцией человеческого бытия, человеческой коммуникации и единственным неисчерпаемым источником человеческого прогресса. Оно составляет основу интеллекта как созидателя социального и культурного капитала. Понимание проявляет себя в миллиардах коммуникативных интеракций и для своей реализации нуждается в позитивных социальных ценностях. Реализация в отечественной идеологии культурологической 
парадигмы есть путь к такому «социуму знаний», но пока лишь в виде теоретических интенций, но не на практике.

\section{Заключение}

Таким образом, кратко резюмируя, можно сказать, что идеологические трансформации последних десятилетий связаны с постепенным переходом к культурологической парадигме цивилизационного развития. Но это все произошло лишь виртуально, а реально сторонники сырьевой парадигмы («нефтяной трубы») и милитаризации невольно сдерживают переход к культурно-цивилизационной модели. Культурно-цивилизационная модель предполагает доминирование «экономики знаний», «досуговой экономики», экоэкономики, ориентацию на приоритет социального и культурного капитала.

В эпоху информационной глобализации в социальной практике управления и в политическом дискурсе управления культурой доминирует технократическая ориентация, которая коррелятивна затратно-ресурсной форме развития экономики и науки. Ведь единственно неограниченной формой ресурсов является интеллект, а его культурносимволической формой воплощения - текст, в широком смысле этого слова, как предметная знаково-символическая форма воплощения знаний. Не случайно в постмодернистской философии метафора текста имеет универсальную онтологизацию. Она соответствует интенции информационной цивилизации на ведущую роль информационно-интеллектуального производства.

В любой экономике, а в «экономике знаний» особенно, доминирование гуманитарной парадигмы необходимо для того, чтобы учить субъекта творчества интеллектуальной активности рефлексивного понимания. Демократическое гражданское общество предполагает, что его граждане есть полноправные, суверенные, автономные субъекты самосознания, рефлексии. В противном случае они как субъекты коммуникации окажутся неспособны вести диалог, результирующей функцией которого является истина. Понимающее критическое размышление является основой рефлексии, которая в языковой и риторической форме выглядит как интерпретация. Все эти факторы и их взаимодействие являются первостепенными в совершенствовании общего образования и в развитии культурного капитала как основы прогресса в «обществе знания».

Реализация супериндустриальной модели предполагает (1) широкую демократизацию гражданского общества как основу социального строя России в противовес авторитаризму и бюрократии, (2) развитую систему механизмов самоорганизации в обществе, культуре, науке, а не развитие по указке чиновника, (3) ведущую роль гуманитаризации в науке, образовании, культуре, (4) наличие и ведущую роль стратегических планов и ориентиров (на 20-30-50 лет), а не латание дыр методом проб и ошибок.

\section{Список литературы}

1. Богин Г.И. 2001. Обретение способности понимать: Введение в филологическую герменевтику. Тверь., Твер. Гос. Ун-т, с. 260.

2. Гриценко В.П. 2019. О проекте модернизации системы подготовки и аттестации научных кадров для региональных вузов. Культурные и научно-образовательные стратегии по реализации национальных проектов-2024. В кн.: Материалы I Международной научнопрактической конференции (Краснодар, 17-18 октября 2019 г.). Краснодар, Краснодарский государственный институт культуры: 66-70.

3. Игнатова В.С., Римский В.П. 2012. Проблема «традиции-инновации» и генезис научноинновационных субкультур (культурно-цивилизационный контекст). Наука. Искусство. Культура, № 1: 34-57.

4. Люсый А.П. 2013. Московский текст. Текстологическая концепция русской культуры. М., Издательский дом «ВЕЧЕ»; ООО «Русский импульс»: 186-187.

5. Основы государственной культурной политики. 2014. http://base.garant.ru /70828330/ (дата обращения: 05 декабря 2019). 
6. Петров М.К. 1991. Язык. Знак. Культура. М., Наука, 192 с.

8. Fukuyama, F. 2001. Social capital, civil society and development. Third World quarterly. Tom.22, No. 1: 7-20.

\section{References}

1. Bogin G.I. 2001. Obretenie sposobnosti ponimat': Vvedenie v filologicheskuyu germenevtiku [Gaining the ability to understand: an Introduction to philological hermeneutics.]. Tver`: Tver. Gos. Un-t, 260 p. (in Russian)

2. Gricenko V.P. 2019. O proekte modernizacii sistemy podgotovki i attestacii nauchnyh kadrov dlya regional'nyh vuzov. Kul'turnye i nauchno-obrazovatel'nye strategii po realizacii nacional'nyh proektov-2024. [Cultural, scientific and educational strategies for the implementation of national projects2024] In: Materials of the I International scientific and practical conference (Krasnodar, October 17-18, 2019). Krasnodar, Krasnodarski1̌ gosudarstvenny̌̌ institut kul'tury: 66-70. (in Russian)

3. Ignatova V.S., Rimskij V.P. 2012. Problema «tradicii-innovacii» $\mathrm{i}$ genezis nauchnoinnovacionnyh subkul'tur (kul'turno-civilizacionnyj kontekst). [The problem of "tradition-innovation" and the Genesis of scientific and innovative subcultures (cultural and civilizational context)]. Nauka. Iskusstvo. Kul'tura, № 1: 34-57.

4. Lyusyj A.P. 2013. Moskovskij tekst. Tekstologicheskaya koncepciya russkoj kul'tury. [Moscow text. Textual concept of Russian culture]. M., Izdatel'skiı̌ dom «VECHE»; OOO «Russkiǐ impul's»: 186-187.

5. Osnovy gosudarstvennoj kul'turnoj politiki [Fundamentals of state cultural policy]. 2014. http://base.garant.ru/70828330/ (data obrashcheniya: 05 dekabrya 2019) (in Russian)

6. Petrov M.K. 1991. YAzyk. Znak. Kul'tura [Language. Sign. Culture.]. M., Nauka, 192 p.

7. Fukuyama, F. 2001. Social capital, civil society and development. Third World quarterly. Tom.22, No. 1: 7-20.

\section{ИНФОРМАЦИЯ ОБ АВТОРЕ}

\section{Опошнянский Алексей Валентинович,} кандидат философских наук, доцент кафедры гуманитарных и социальноэкономических дисциплин Краснодарского высшего военного авиационного училища лётчиков имени Героя Советского Союза А.К. Серова, г. Краснодар, Россия

\section{INFORMATION ABOUT THE AUTHOR}

Alexey V. Oposhnyansky, Candidate of Philosophy, Associate Professor of the Department of Humanitarian and Socio-Economic Disciplines Krasnodar Higher Military Aviation School of Pilots named after Hero of the Soviet Union A.K. Serov Krasnodar, Russia 